\title{
Assessing alternative production options for eco-efficient food supply chains using multi-objective optimization
}

\author{
Aleksander Banasik ${ }^{1}$ • Argyris Kanellopoulos ${ }^{1}$ - G. D. H. Claassen ${ }^{1}$ • \\ Jacqueline M. Bloemhof-Ruwaard ${ }^{1}$ • Jack G. A. J. van der $\operatorname{Vorst}^{1}$
}

Published online: 25 April 2016

(c) The Author(s) 2016. This article is published with open access at Springerlink.com

\begin{abstract}
Due to tremendous losses of resources in modern food supply chains, higher priority should be given to reducing food waste and environmental impacts of food production. In practice, multiple production options are available, but must be quantitatively assessed with respect to economic and environmental performances before they are adopted in food supply chains. The objective of this paper is to develop a mathematical model that can be used for such a quantitative assessment of alternative production options that are associated with different ways to deal with waste in food supply chains, i.e. prevention, recycling, and disposal of food waste. We develop a multi-objective mixed integer linear programming model to derive the set of eco-efficient solutions corresponding to production planning decisions. Environmental performance of the chain is expressed with an indicator based on exergy analysis, which has the potential to capture other commonly used indicators, such as energy consumption, fuel consumption, and waste generation, and express them in a single value. This simplifies the calculation of the eco-efficient frontier, and enables its intuitive graphical representation, which is much easier to communicate to the involved decision makers. The applicability of the developed model is demonstrated on a real-life industrial bread supply chain in the Netherlands. Results confirm the findings from literature that prevention is the best waste management strategy from environmental perspective. The advantages of using exergy as an indicator to capture the environmental performance is demonstrated by comparing the outcomes to other commonly used indicators of environmental performance. We illustrate the potential of studying food production planning decision problems in a multi-objective context, and demonstrate the applicability of the model in the assessment of alternative production options.
\end{abstract}

Keywords Multi-criteria decision making · Sustainability · Food production · Production planning · Exergy

Aleksander Banasik

Olek.Banasik@wur.nl

1 Operations Research and Logistics, Wageningen University, Hollandseweg 1, 6706 KN Wageningen, The Netherlands 


\section{Introduction}

Until recently, food production focused mainly on delivering high quality products at low costs with only secondary attention on environmental impacts, food losses, and depletion of natural resources. However, increasing awareness of environmental issues, increasing scarcity of resources, social pressure and new regulations force companies to reconsider their operations (Chaabane et al. 2012). A major concern in Food Supply Chains (FSCs) is related to food waste (Shukla and Jharkharia 2013). According to FAO (2013) about 1.6 billion tons corresponding to one-third of all food produced for human consumption is lost or wasted. Processing and distribution of food are responsible for approximately 0.4 billion ton of food wastage. To remain competitive, FSCs are challenged to adopt new technologies that reduce or valorise food waste. These technologies can contribute to maintaining or increasing economic output and reducing environmental impact of current operations i.e. achieving what has been defined as eco-efficiency (Braungart et al. 2007). Quantitative assessment of both the economic and environmental benefits of these alternative technologies and production options increase the adoption rate and facilitates managerial decision making. Production planning models that optimize decisions on how, how much, what and when to produce to meet the demand can be used to combine available production options and assess quantitatively the economic and environmental consequences of new technologies.

Most of the production planning literature, i.e. lot sizing, is focussed on discrete (assembly) manufacturing and traditional models have been increasingly refined to incorporate more detail of specific production environments (Quadt and Kuhn 2008; Jans and Degraeve 2008; Clark et al. 2011). Nevertheless, almost all traditional models take the classical principle of optimality for lot-sizing as the ultimate objective, i.e. find the best compromise between total production costs on the one hand and total inventory-holding costs on the other hand (Claassen and Hendrix 2014). In their special issue on lot-sizing, Clark et al. (2011) stated that changes in the philosophy of production planning and control triggered the debate about whether or not lot-sizing as a trade-off between setups and stocks should be the ultimate objective in production planning. The authors noticed a lack of research on (i) more realistic and practical variants of lot-sizing models and (ii) the effect of using real life instances to carry out computational experiments. To explore eco-efficient logistical structures with production planning models it is important to be able to quantify the potential economic output for different levels of environmental impact (and vice versa). Consequently, multi-objective optimization is required.

Only a few studies apply multi-objective optimization in food supply chains to account for economic and environmental indicators (Govindan et al. 2014; Soysal et al. 2014; Validi et al. 2014; Akkerman et al. 2009), but focus mainly on optimizing strategic distribution and location/allocation problems, and not production planning decisions. In these aforementioned studies $\mathrm{CO}_{2}$ emissions are used as an indicator for environmental performance. In multiobjective optimization models for supply chain management environmental performance of a SC is expressed by various indicators, such as greenhouse gases (GHG) emitted (Harris et al. 2011; Chaabane et al. 2011; Aramyan et al. 2011), energy consumed (Quariguasi Frota Neto et al. 2009; Van Der Vorst et al. 2009; Zanoni and Zavanella 2012), solid waste produced (Quariguasi Frota Neto et al. 2009; Paksoy et al. 2010), or water consumed (Oglethorpe 2010; You et al. 2012). An important drawback of these indicators is the lack of a uniform metric for the comparison of different substances (e.g. different emissions, waste produced, energy and water consumed) including their impacts (Coatanéa et al. 2006; Wall 2010). Moreover, often a single indicator is chosen in optimization models to express the environmental performance 
for computational purposes and for easiness of communicating results with the involved decision makers. To overcome these shortcomings aggregated environmental indicators have been proposed, such as Cumulative Energy Demand (CED) (Quariguasi Frota Neto et al. 2009) and total GHG emissions represented in tons of $\mathrm{CO}_{2}$ equivalent. However, these metrics have been criticized because they concentrate only on a single aspect of environmental performance (e.g. CED on energy use, $\mathrm{tCO}_{2} \mathrm{e}$ on greenhouse gas emissions). An alternative approach to quantify environmental impact in a single unit is based on the concept of exergy. Exergy analysis is an objective assessment method that has been applied in many fields, e.g. chemical sector, environmental engineering; and recently also in food industry (Zisopoulos et al. 2015). Despite its advantages, exergy analysis has not been used in combination with economic performance in optimization models to support decision making in food supply chains.

This study adds to literature on supply chain management by (1) presenting a realistic variant of a lot sizing model used to assess alternative production options, and (2) providing a model to support production planning decisions in a food supply chain while taking into account economic and environmental criteria. The objective of this paper is to develop a mathematical model that can be used to optimise production decisions in food supply chains by quantifying trade-offs between (most of the time) conflicting economic and environmental indicators, and by exploring alternative production options (at food production chain level) with specific attention to food waste. This is achieved by developing a multi-objective multiitem capacitated lot-sizing optimization model. The applicability of the model to a real-life problem is shown on a bread supply chain in the Netherlands, where the total amount of food waste throughout the complete chain constitutes approximately $30 \%$ of total bread production (Zisopoulos et al. 2015; Blonk 2006) accounting for 330 thousand tons of bread waste annually. On the bread supply chain the differences in optimal solutions and trade-off curves are illustrated when environmental performance is expressed with different measures, which are: exergy loss, $\mathrm{CO}_{2}$ equivalent, and waste generated. Our analysis focuses on the eco-efficient solutions, i.e. solutions for which it is impossible to improve one objective, without worsening the other. Eco-efficient solutions provide insights in the costs for a unit improvement in environmental impact and vice versa.

The paper is structured as follows. The next section discusses the conceptual model, in which we describe three options to produce a food product, introduce the concept of exergy analysis, which is used for quantification of environmental impact, and present the multi-objective mixed integer linear programming (MILP) model used to support production planning decisions in a food supply chain. Section 3 describes the bread supply chain in the Netherlands including three alternative bread production options, discusses the data, and gives the results of the mathematical model. Section 4 presents sensitivity analysis on important parameters of the mathematical model for industrial bread production. The last section presents conclusions.

\section{Problem description}

A typical food supply chain comprises the following links: suppliers of raw materials, processing facility, and retail outlet. Our analysis starts with procurement of raw materials (production of raw materials is not taken into account) and ends with meeting customer's demand. We look at a perishable food product that becomes waste if it is not sold on the day of production. 


\subsection{Alternative production options}

Alternative production options are available in practice to produce a food product. Each production option, due to its unique production structure and processing steps, is inherently associated with (at least) one waste management option. According to Papargyropoulou et al. (2014) the most favourable option to deal with waste is prevention followed by re-use, recycle, recovery, and disposal. Three food waste management options are considered here: disposal, prevention, and recycling of food waste (Fig. 1). Disposal of waste refers to a situation when the product is not sold before its due date, and is not recycled in the studied food supply chain. Prevention of waste, as considered in this paper, is possible via potential storage of products in controlled conditions, therefore extending product's shelf life. Recycling of waste allows valorising not sold products by using processed waste as a raw material for production, therefore reducing the need for other raw materials.

Because the decision on production quantities must be made before the actual demand is exactly known, we assume that each production option is associated with a pre-defined amount of waste stream calculated as a fraction of total production with a given option. To compare the alternative production options, production planning models are needed that take both economic and environmental criteria into account.

Optimizing production planning decisions gives insights in the most preferable production option, which in turn will have an impact on the design of a food supply chain. Moreover, optimizing production planning decisions is important for improving eco-efficiency, because each production option has an effect on both the total amount of waste produced, and on other environmental indicators, such as water consumed, or emitted GHG. Producing a food product that has the potential to prevent waste may require additional processing steps or temperature controlled storage leading to additional energy consumption at different links of a chain. A food product that can be recycled may require an additional waste processing step and additional fuel consumption due to transportation. Therefore two aspects play an important role. First, the whole chain should be taken into account to avoid sub optimization, i.e. improving the performance of a single link of a supply chain, at the greater expense of the performance in other links. Secondly, multiple environmental indicators (next to an economic indicator) must be considered when assessing the impact of each production option. However, in cases of more than two objectives in multi-objective optimization models there is no guarantee of efficiency for the obtained solution and computation times may increase

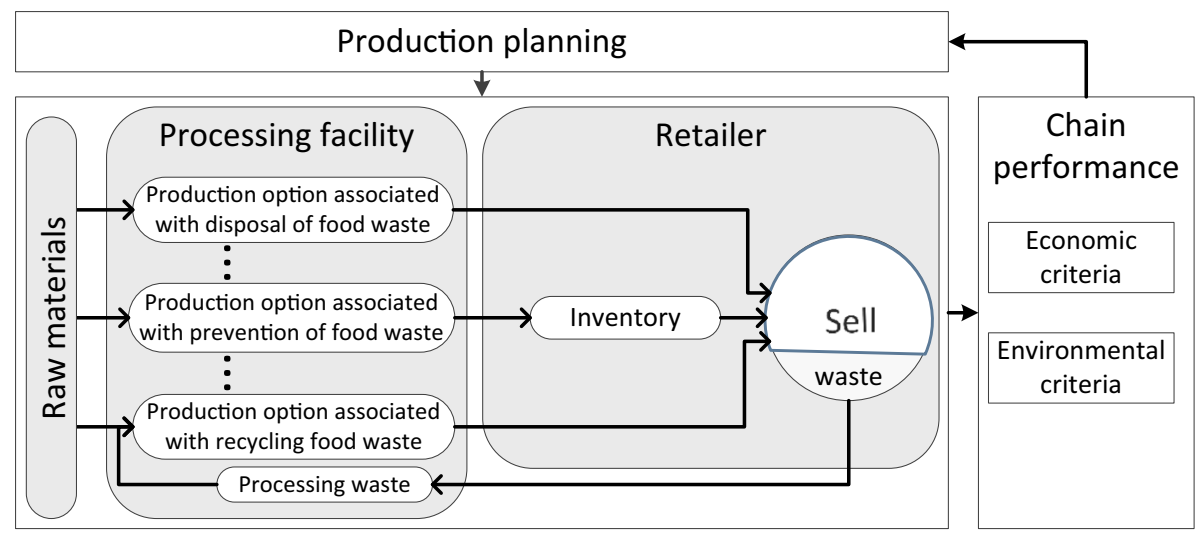

Fig. 1 Conceptual model for assessing alternative production options with multi-objective production planning 
substantially with the number of conflicting objectives (Mavrotas 2009). To simplify the problem we use an integrated indicator based on exergy analysis that has the potential to capture other commonly used environmental indicators and express them in a single value.

\subsection{Environmental assessment: exergy analysis}

Exergy analysis is based on the basic concepts in thermodynamics and it is a suitable scientific concept to study the environmental impact because, unlike other single metric indicators, it measures all inputs and outputs in a single unit (MJ), making the results visible and conclusions easy to draw (Apaiah et al. 2005, 2006; Wall 2010). Exergy analysis has been widely used as an assessment of environmental impact in various fields, including the chemical industry (Cortez et al. 1997; Morris 1991) and, more recently, the food industry (Apaiah et al. 2006; Draganovic et al. 2013). Exergy measures the ability of a source to produce useful work (measured in $\mathrm{MJ}$ ) that gives a numerical value not only to the quantity but also to the quality of the energy use (Apaiah et al. 2005, 2006). In contrast to energy, exergy is exempt from the law of conservation, and in all real life processes exergy input always exceeds exergy output (Apaiah et al. 2006), which means that some exergy is irreversibly lost in each processing step. An exergy balance applied to a process explains how much exergy supplied as an input to the considered system has been irretrievably lost by the process (Kotas 1995). It enables the determination of the location, types and magnitudes of wastes (streams that still contain exergy) and losses (exergy irreversibly lost). Exergy analysis has also the potential to characterize each product by an exergetic value based on product's chemical composition. If a product is not (re)used and becomes waste, then the exergetic value of the product is considered as a loss. As a result the production process, transportation and waste can be quantified based on exergy losses, and exergy can be regarded as an umbrella indicator for the assessment of environmental impact. The concept of exergy is used in this paper to assess environmental impact of alternative production options (defined by practitioners) that are associated with at least one waste management option considered i.e. disposal, prevention and recycling of food waste.

\subsection{Mathematical model}

The mathematical model for production planning in a food supply chain is formulated as a multi-objective mixed integer linear programming model with economic and environmental objectives. We formulated a multi-item capacitated lot-sizing model in line with Pochet and Wolsey (2006) and tuned it for comparing alternative production options that determine different ways of dealing with waste (dispose, prevent, or recycle waste). The economic objective is expressed in monetary units and represented by profit. The environmental impact is expressed in megajoules and represents exergy losses. The presented model supports decisions on startups of production and production amounts in each time period for each considered product type and production option.

Index sets

$I \quad$ Set of all product types

$B \quad$ Set of all production options

$P \subset B \quad$ Set of production options (associated with prevention of food waste) allowing for storage of products

$R \subset B \quad$ Set of production options (associated with recycling food waste) that include (processed) waste as a raw material in production 
$R^{\prime} \subset B \quad$ Set of production options resulting in products, which waste can be recycled in production option(s) $r \in R$

$T \quad$ Set of time periods

\section{Decision variables}

$X_{i, b, t} \quad$ amount of product $i \in I$ produced with production option $b \in B$ in time $t \in T$ $H_{i, b, t} \quad$ inventory level of product $i \in I$ produced according to production option $b \in P$ at the end of time period $t \in T$

$Y_{i, b, t} \quad$ binary variable indicating if product $i \in I$ is made with production option $b \in B$ in time period $t \in T$

$S_{i, b, t} \quad$ amount of product $i \in I$ produced with option $b \in B$ on shelf in retail outlet in period $t \in T(\mathrm{~kg})$

$W_{i, b, t} \quad$ amount of waste from product $i \in I$ produced with option $b \in R^{\prime}$ recycled and used in period $t \in T(\mathrm{~kg})$

\section{Parameters}

$d_{i, t} \quad$ demand for product $i \in I$ in period $t \in T(\mathrm{~kg})$

$v_{i} \quad$ volume of product $i \in I\left(\mathrm{~m}^{3} / \mathrm{kg}\right)$

$b_{i} \quad$ processing time of product $i \in I,(\mathrm{~h} / \mathrm{kg})$

$c a p \_b \quad$ daily processing capacity in the processing facility) (h)

$c a p \_h \quad$ holding capacity in the retail outlet $\left(\mathrm{m}^{3}\right)$

$m_{i, b} \quad$ large constant

$z_{i, b} \quad$ fraction of product $i \in I$ produced with option $b \in B$ wasted at the retail outlet $(\%)$

$p b_{i, b} \quad$ selling price of product $i \in I$ produced with option $b \in B(€ / \mathrm{kg})$

$c p_{i, b} \quad$ costs associated with producing one $\mathrm{kg}$ of product $i \in I$ produced with option $b \in B$ delivered to the retail outlet $(€ / \mathrm{kg})$

ch holding costs per kilogram per day $(€ / \mathrm{kg})$

$c y_{i, b} \quad$ production setup costs for product $i \in I$ produced with option $b \in B(€)$

$e p_{i, b} \quad$ total exergy losses for producing one $\mathrm{kg}$ of product $i \in I$ produced with option $b \in B$ delivered to the retail outlet $(\mathrm{MJ} / \mathrm{kg})$

eh exergy losses associated with holding $1 \mathrm{~kg}$ of product in inventory per day $(\mathrm{MJ} / \mathrm{kg})$

$e w_{i, b} \quad$ chemical exergy in $1 \mathrm{~kg}$ of product $i \in I$ produced with option $b \in B(\mathrm{MJ} / \mathrm{kg})$

$r_{i, b} \quad$ fraction of product waste $i \in I$ (based on recipe) needed as an ingredient to produce $1 \mathrm{~kg}$ of product with production option $b \in R(\%)$

$\max \left\{\sum_{i \in I, b \in B, t \in T} p b_{i, b}\left(1-z_{i, b}\right) S_{i, b, t}-\sum_{i \in I, b \in B, t \in T} c p_{i, b} X_{i, b, t}-\sum_{i \in I, b \in B, t \in T} c h H_{i, b, t}-\sum_{i \in I, b \in B, t \in T} c y_{i, b} Y_{i, b, t}\right\}$

$\min \left\{\sum_{i \in I, b \in B, t \in T} e p_{i, b} X_{i, b, t}+\sum_{i \in I, b \in B, t \in T} e h H_{i, b, t}+\sum_{i \in I, b \in B, t \in T} e w_{i, b}\left(z_{i, b} S_{i, b, t-1}-W_{i, b, t}\right)\right\}$ 
Subject to

$$
\begin{aligned}
& \sum_{b \in B}\left(1-z_{i, b}\right) S_{i, b, t}=d_{i, t} \\
& \text { for all } i \in I, t \in T \\
& X_{i, b, t}-S_{i, b, t}=H_{i, b, t}-H_{i, b, t-1} \quad \text { for all } i \in I, b \in B, t \in T \\
& \sum_{i \in I, b \in B \backslash P, t \in T} H_{i, b, t}=0 \\
& X_{i, b, t} \leq m_{i, b} Y_{i, b, t} \\
& \sum_{i \in I, b \in B} b_{i} X_{i, b, t} \leq c a p \_b \\
& \sum_{i \in I, b \in B} v_{i} H_{i, b, t} \leq c a p \_h \\
& z_{i, b} S_{i, b, t-1} \geq W_{i, b, t} \\
& \sum_{b \in R} r_{i, b} X_{i, b, t}=\sum_{b \in R^{\prime}} W_{i, b, t} \\
& \sum_{i \in I, b \in B}\left(H_{i, b, 0}+S_{i, b, 0}\right)=0 \\
& Y_{i, b, t} \in\{0,1\}
\end{aligned}
$$

Objective function (1) specifies the economic objective function, and refers to maximization of profit over the planning horizon. Profit is defined as revenues minus production, inventory and set-up costs. Total revenues are related to product sales at the retail outlet while total production costs are associated with costs related to sourcing of raw materials, energy, transportation, and labour. Inventory costs are related to energy consumption of inventory due to storage (in a temperature controlled conditions), while setup costs (such as cleaning and warm-up of machines) are related to production. Objective function (2) refers to the environmental objective and aims to minimize total exergy losses related to production, holding and waste. Production losses include exergy losses related to fuel consumption in transportation of raw materials to the processing facility, transportation of products to the retail outlet, as well as exergy losses related to energy consumption in all processing steps in the processing facility. Holding losses relate to energy consumption due to temperature controlled conditions in the inventory in the retail outlet. Waste losses are calculated by multiplying total amount of wasted product with the exergetic value of $1 \mathrm{~kg}$ of product.

We assume that the demand is given per product type and independent of the production option. Constraints (3) ensure that demand for each product type is met while taking into account the amount of waste in the retail outlet. Constraints (4) ensure that any surplus of products is stored in an inventory. Constraint (5) implies that only products associated with preventing waste option can be held in inventory. Constraints (6) ensure that the set up binary variable gets value 1 if production of a particular product type takes place. Constraints (7) and (8) correspond to respectively production capacity in the processing facility and holding capacity. Constraints (9) ensure that the amount of recycled waste does not exceed available waste. Constraints (10) correspond to the amount of recycled waste needed to produce product made with recycled material. Constraint (11) sets the starting inventory and amount of product on the shelf at time period $\mathrm{t}=0$. 


\section{Case study}

In this section we apply the general model to a specific case study of a bread supply chain in the Netherlands. We consider a bread supply chain with fixed raw material providers, a single industrial bakery, and supermarkets. We consider two bread types: white tin bread, and brown bun. These two bread types are considered to be the two extreme recipes, representative for the complete variety of bread products. Each bread type can be produced with one of the three available production options resulting in freshly baked bread (waste disposal), parbaked bread (waste prevention), or fermented breadcrumb bread (waste recycling). A time period of a week (Monday to Sunday) is considered to be representative, and we optimize a production plan for that time period taking into account fluctuations in demand throughout different weekdays.

The main raw materials needed for bread production are wheat flour, whole meal, water, yeast, salt, and bread improver. At the bakery the raw materials are combined in a mixing machine to produce dough. After the mixing phase, the dough is put on a conveyor for further processing steps. Dough is fermented for $1 \mathrm{~h}$, and subsequently divided and shaped in a desired form by a machine. Next, it is left for one more hour for another fermenting step, called proving. Finally the baking, cooling/freezing, and packing takes place, after which the products can be transported to the supermarkets.

Bread products are commonly transported from an industrial bakery to supermarkets every morning. A key characteristic of freshly baked bread in the Netherlands is its short shelf life. Most of the bread products must be sold on the production day due to quality characteristics and consumer acceptance. Freshly baked bread products not sold at production day become waste. Because the decision on production quantities is commonly made before the actual (exact) demand is known, supermarkets usually order more bread than the actual demand in order to avoid stock outs. This results in a large waste stream in supermarkets.

In the remainder of this section we describe three alternative bread production options evaluated in this study: (i) freshly baked bread, (ii) par-baked bread and (iii) fermented breadcrumb bread.

Current practice for industrial bread production in the Netherlands is the so-called freshly baked bread (associated with disposal of food waste as presented in Fig. 1, and corresponding to production option $\mathrm{b}=1$ ), referred to as fresh bread. Fresh bread production in this paper refers to baking the products at the bakery and transporting the products daily to the supermarkets. In this traditional production option, after the dough preparation phase, breads are fully baked at the industrial bakery. Bread loaves are then automatically packed, loaded in returnable crates, and transported to supermarkets by (non-conditioned) trucks. In the supermarkets, fresh breads are directly put on shelves and must be sold on delivery day, otherwise it will become waste. It is estimated that $11 \%$ of fresh bread is wasted at supermarkets (Zisopoulos et al. 2015; Blonk 2006). Currently, wasted bread products are typically given away for animal feed production.

Par-baked bread production (associated with prevention of food waste as presented in Fig. 1 , and corresponding to production option $b=2$ ) is an alternative production option that has the potential to prevent bread waste. The main difference compared to the fresh bread production is that par-baked bread production involves two baking steps: a partial bake at the industrial bakery and a final bake at each supermarket (consequently losing economies of scale). Breads are first partially baked (for the same amount of time as fresh bread, but at lower temperature), and subsequently frozen. Frozen bread loafs are loaded in returnable crates and transported to supermarkets in trucks with a refrigeration unit under temperature controlled 
conditions. At the supermarket, par-baked bread can be stored up to 9 months in freezing conditions that entail electricity consumption. The final baking step is performed in response to the observed demand, which implies that quantities of wasted bread are substantially less compared to fresh bread production.

Fermented breadcrumb bread production (associated with recycling of food waste as presented in Fig. 1, and corresponding to production option $b=3$ ) is an alternative that allows to recycle bread waste (Zisopoulos et al. 2015). Commonly, bread products not sold on the same day as being produced are considered as waste. However, the recipe for fermented breadcrumb bread production includes an ingredient that is based on bread leftovers. To produce fermented breadcrumb, the bread not sold at the supermarket should be collected and transported back to the bakery. At the bakery, the leftover bread is mixed with water and enzymes, and subsequently fermented and chilled. This so-called fermented breadcrumb is mixed with other raw materials defined by the recipe for fermented breadcrumb bread. Further processing is in line with processing steps for fresh bread production.

Decisions to be taken by management include the frequency of production, batch sizes, and (if par-baked bread is produced) the amount of inventory held. The alternative options can affect the production planning and logistical structure of the current bread supply chain with substantial consequences to economic and environmental performance of the chain as a whole.

All bread types can be produced according to the three described alternatives: produced at an industrial bakery (fresh bread, $b=1$ ), partially baked at the bakery and final baked in the supermarkets (par-baked bread, $b=2$ ), or prepared using processed bread waste, thus reducing the need of other ingredients (fermented breadcrumb bread, $b=3$ ). Fresh bread production is associated with the least processing and transportation per kilogram of bread produced, but entails high amounts of food waste (amount of fresh bread exceeds the demand to prevent stock outs). Production of par-baked bread allows reducing the amount of waste to a minimum (the final baking step is carried out to react to current demand), but requires more energy consumption due to an additional baking step, and electricity consumption in storage. Production of fermented breadcrumb bread is a way to valorise bread waste, but is associated with additional processing steps compared to fresh bread production.

\subsection{Data}

Data and assumptions are collected and assessed with industrial partners as well as collaborating scientists from food processing, who assess the environmental impact. Exergy analysis for this case study, the calculation of exergy losses per processing step, and all assumptions related to activities carried out to produce a food product (including fuel consumption for transportation, electricity and natural gas consumption for processing) are presented in Zisopoulos et al. (2015). Selling prices for bread products are the same for each production option, and the demand for breads (Fig. 2) is aggregated and given per bread type, not per production option. In other words, a product type produced with different production options are perfect substitutes. We aggregate all supermarkets in a region into one, and thus demand data of the single (aggregated) supermarket refers to demand of a complete region supplied by a single industrial bakery.

In the bakery, equipment used for processing raw materials (mixing machine and conveyor belt) is supplied by electricity, and a continuous oven is heated by natural gas. Energy usage differs for each production option, because each option determines the temperature needed for baking. An industrial oven can be used efficiently for $90 \%$ of a day ( $21.6 \mathrm{~h}$ per day) and has the capacity to bake $1920 \mathrm{~kg}$ of white tin bread per hour, and $1080 \mathrm{~kg}$ of brown buns per hour. 


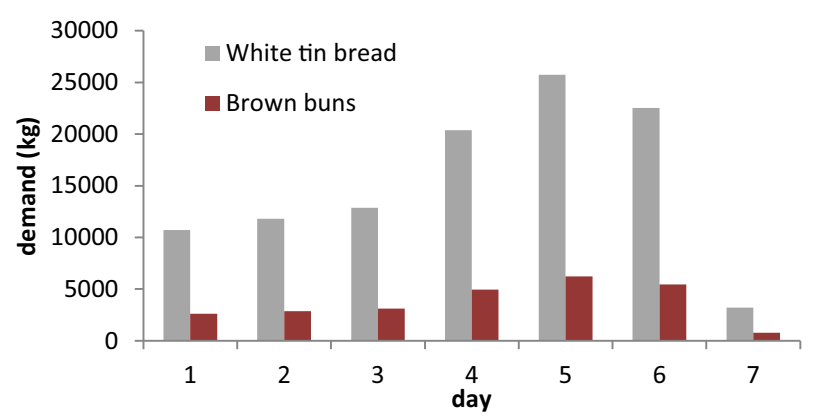

Fig. 2 Demand for different bread types throughout a week (day 1 refers to Monday, day 2 to Tuesday etc.)

Table 1 Exergy losses in each production and transportation step (MJ/kg), chemical exergy per $1 \mathrm{~kg}$ of bread $(\mathrm{MJ} / \mathrm{kg})$, and production and transportation costs (€/ $\mathrm{kg})$ for fresh, par-baked, and fermented breadcrumb

\begin{tabular}{|c|c|c|c|c|c|c|}
\hline \multirow{2}{*}{$\begin{array}{l}\text { Values of parameters in } \\
\text { the objective functions }\end{array}$} & \multicolumn{3}{|l|}{ White tin } & \multicolumn{3}{|c|}{ Brown bun } \\
\hline & Fresh & Par-baked & $\begin{array}{l}\text { Ferm. } \\
\text { bread. }\end{array}$ & Fresh & Par-baked & $\begin{array}{l}\text { Ferm. } \\
\text { bread. }\end{array}$ \\
\hline $\begin{array}{l}\text { Total exergy losses in } \\
\text { production and } \\
\text { transportation }(\mathrm{MJ} / \mathrm{kg})^{\mathrm{a}}\end{array}$ & 4.47 & 5.64 & 4.79 & 4.73 & 5.39 & 5.53 \\
\hline $\begin{array}{l}\text { Chemical exergy per } 1 \mathrm{~kg} \text { of } \\
\text { bread }(\mathrm{MJ} / \mathrm{kg})\end{array}$ & 11.48 & 11.48 & 11.46 & 12.72 & 12.72 & 12.71 \\
\hline Setup costs (€/setup) & 1000 & 1000 & 1000 & 1000 & 1000 & 1000 \\
\hline Production costs $(€ / \mathrm{kg})^{\mathrm{a}}$ & 0.66 & 0.82 & 0.68 & 0.97 & 1.15 & 0.97 \\
\hline Selling price $(€ / \mathrm{kg})$ & 1.61 & 1.61 & 1.61 & 2.75 & 2.75 & 2.75 \\
\hline $\begin{array}{l}\text { Bread waste at the } \\
\text { supermarket (\% of total } \\
\text { production) }\end{array}$ & 11.2 & 0 & 11.2 & 11.2 & 0 & 11.2 \\
\hline $\begin{array}{l}\text { Total emissions in production } \\
\text { and transportation } \\
\left(\mathrm{g} \mathrm{CO}_{2} \mathrm{e} / \mathrm{kg}\right)\end{array}$ & 303 & 414 & 343 & 298 & 404 & 356 \\
\hline
\end{tabular}

$\overline{{ }^{a} \text { Detailed data on exergy losses and production costs per activity are given in Appendices } 1 \text { and 2, respectively }}$

At the supermarket, the environmental impact is associated with energy consumption related to (final) baking of par-baked breads, electricity consumption in storage room, and wasted bread products, i.e. bread is considered wasted if it cannot be sold the same day as being produced and if it is not recycled and used for (fermented breadcrumb bread) production.

Total exergy losses associated with production and transportation are expressed in a single value per kilogram of product produced for each bread type, and each production option (Table 1). This single value includes exergy losses associated with transport of raw materials, mixing, fermenting, dividing, proving, baking, transport of bread, and final baking per kilogram of product produced. Table 1 also provides data on other environmental indicators considered, i.e. bread waste, and total emission in production and transportation.

We used average data to fix the amount of bread waste at the supermarket. The amount of bread wasted is calculated as a fraction of total demand (assuming overproduction to avoid stock outs). Each production option entails a different amount of wasted bread, e.g. par-baked 
bread entails the lowest bread losses, as management of the bakery in the supermarket can react to low stock of bread products, and perform the final baking step. Based on industrial data and discussion with experts we assume that production of fresh bread, par-baked bread, and fermented breadcrumb bread entails 11, 0, and $11 \%$ waste, respectively. Each type of bread produced with each option is associated with a different chemical exergy value (Table 1). This value is considered as exergy loss for each kilogram of bread product wasted. However, if the leftover bread at the supermarket is recycled and used for fermented breadcrumb bread production, then it is not associated with exergy losses.

Total costs associated with production and transportation (including fuel for transport of raw materials, energy costs at the bakery, labour costs in the bakery, fuel for transport of bread, energy costs for final baking at the supermarket, and labour costs in the supermarket associated with final baking step) are also expressed in a single value per kilogram of bread produced with each production option (Table 1).

Inventory holding costs, as well as exergy losses due to inventory holding, are associated with electricity consumption only, being $0.0005 €$ per kilogram of each product stored per day, and $0.0187 \mathrm{MJ}$ exergy losses per kilogram of each product stored per day. Setup costs associated with starting up the production (e.g. preparing the production line, heating up the ovens, cleaning the machines etc.) are set at $1000 €$ per bread type, per production option.

\subsection{Computational results: optimizing single objectives}

First results of the multi-objective MILP for bread production planning are given in this section. We present the optimal solutions while optimizing single environmental and economic objectives. Optimal solutions indicate the produced quantities of bread including production frequencies. The production planning model for a bread supply chain in the Netherlands was solved using Xpress-IVE version 7.2. The mathematical model comprises 42 binary variables, 192 continuous variables, and 171 constraints. Results are presented in Fig. 3 that shows the daily amounts of bread produced with each production option for the optimal production plans with respect to economic and environmental performance.

The optimal economic production plan for white tin bread is to produce fresh bread daily (Fig. 3a). Variable costs of fresh white tin bread are $26 \%$ lower than for par-baked and $3 \%$ lower than for fermented breadcrumb white tin bread. For production of brown buns, the par-baking option is selected and produced in two days in the considered planning horizon (Fig. 3b). The variable costs of fresh brown buns are $19 \%$ lower than for par-baked bread, which is not enough to compensate for the lower total set-up costs of producing only twice par-baked brown buns. If the baking capacity constraint was removed from the model formulation, production of par-baked brown buns would have taken place on the first day to cover weekly demand.

When exergy losses are minimized, the optimal production plan includes daily production of par-baked bread for both bread types (Fig. 3c, d). Despite higher exergy losses per unit of par-baked bread produced compared to other production options (Table 1), no bread losses at the supermarket make par-baking option favourable from an environmental point of view.

The optimal economic production plan has a profit of $126,268 €$ and $835,579 \mathrm{MJ}$ exergy losses. The optimal environmental production plan has a profit of $112,172 €$ and $745,415 \mathrm{MJ}$ exergy losses. Therefore, the economic production plan has $12 \%$ more exergy losses than the environmental production plan, whereas the environmental production plan has $11 \%$ less profit than the economic production plan. This finding shows that the two objectives are conflicting for this case study. 


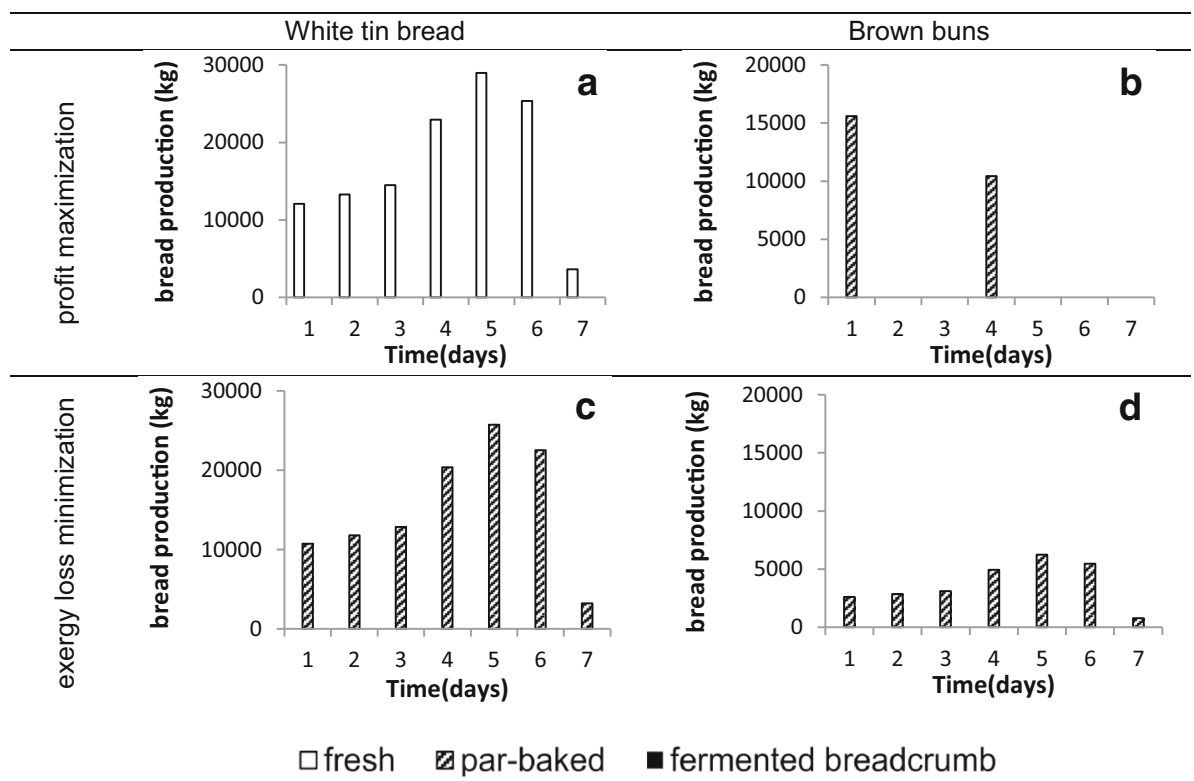

Fig. 3 Optimal production plans with respect to economic (profit maximization) and environmental (exergy losses minimization) objectives

Minimizing the total amount of waste would result in producing par-baked bread (no bread losses) for both bread types. Minimization of total emissions expressed in $\mathrm{CO}_{2}$ equivalents results in fresh bread only, which has the lowest amount emissions for both bread types. Therefore, under current assumptions, using exergy losses as an environmental objective yields the same optimal solution with respect to environment as if waste was used as an objective.

\subsection{Computational results: multi-objective approach}

A number of approaches are available to solve multi-objective optimization problems, among them $\varepsilon$-constraint and weighted sum method are the most widely used (Miettinen 2008). However, weighted sum method, in which the weighted sum of objectives is optimized, is not suitable for our problem because this approach does not find all pareto-efficient points when the solution space is not convex (Chanta et al. 2014; Das and Dennis 1997). Therefore, we selected the $\varepsilon$-constraint to solve the bi-objective optimization problem and to calculate the set of eco-efficient solutions. For a detailed description of the method we refer to Ehrgott (2005).

The eco-efficient solutions are generated by minimizing the environmental objective and varying parametrically (in 10,000 iterations) a lower bound on the profit objective function value in the constraint set. This is performed for three scenarios depending on the environmental objective considered i.e. exergy losses, food waste, and $\mathrm{CO}_{2} \mathrm{e}$.

\subsubsection{Eco-efficient solutions for exergy loss as an environmental objective}

The set of eco-efficient solutions, while taking exergy loss as an environmental objective, is presented in Fig. 4. The "jumps" in between some line segments on the efficient frontier 


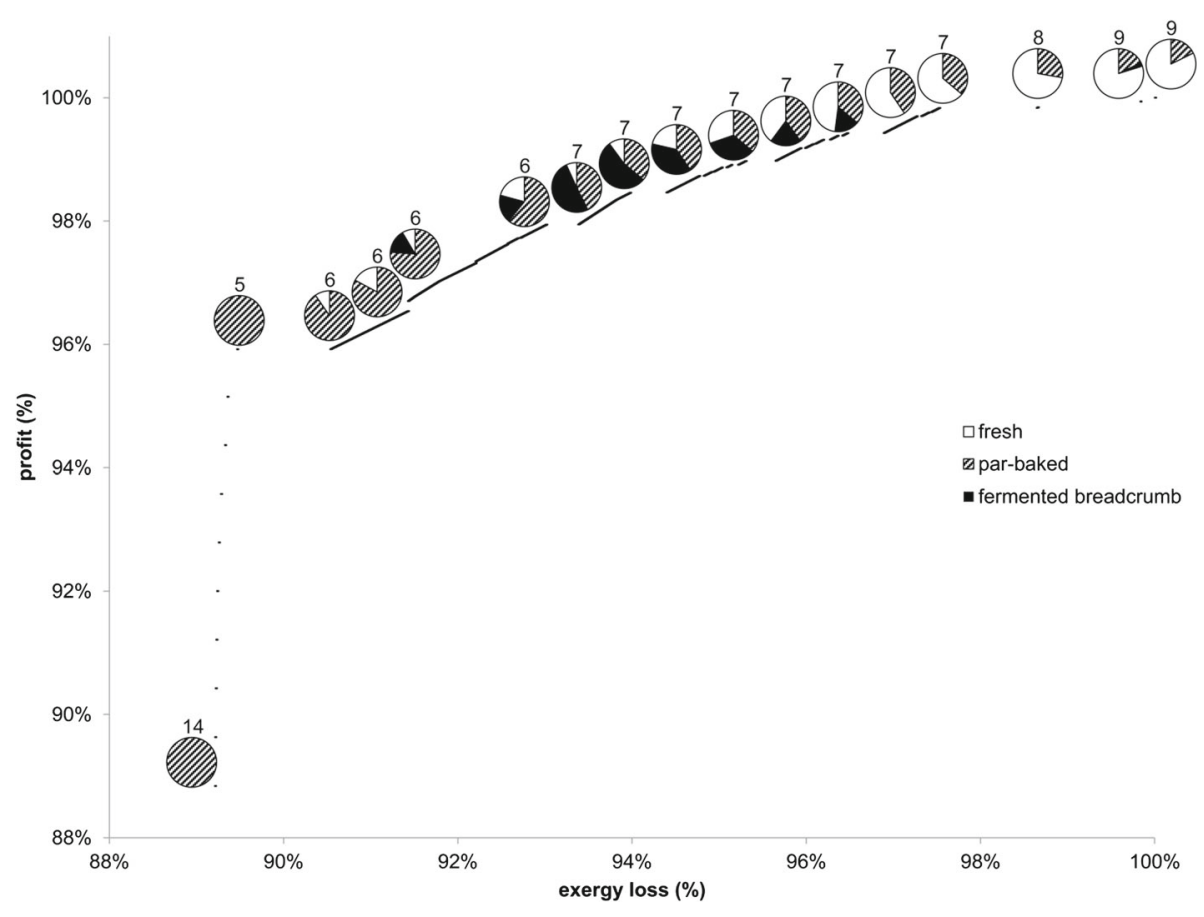

Fig. 4 Trade-off between profit and exergy loss; pie charts above solutions indicate amount of bread produced with each option as a fraction of total (weekly) production; numbers above pie charts indicate total number of setups for both bread types in the considered production plan

are caused by discrete changes in selection of production options or changes in production days of bread types, and are often associated with the number of setups. The total number of setups, when minimizing total exergy losses, is 14 (i.e. producing par-baked bread every day for both bread types). By increasing the lower bound of profit the number of set-ups decreases, while still producing only par-baked bread. After the initial rapid increase in economic objective, the number of setups rises gradually and reaches 9 setups (due to a gradual change in production of par-baked white tin bread to daily production of fresh white tin bread) for the two production plans with the highest economic objective function value.

In all eco-efficient solutions, brown buns are produced only with the par-baking option (note that demand for brown buns corresponds to $19.5 \%$ of total bread demand). Moreover, the production of brown buns is carried out within two days to fulfil the weekly demand (i.e. there are only two setups) in each eco-efficient production plan for profit above $95 \%$ of the maximum profit. Par-baking is also the only production option for white tin bread when minimizing exergy losses. However, production of fresh white tin bread is observed for production plans on the eco-efficient frontier where exergy losses exceed $90 \%$ of exergy losses obtained for best economic production plan (Fig. 4). The number of days when fresh (white tin) bread is produced increases for eco-efficient production plans with increasing profit. At the same time, number of days when par-baked white tin bread is produced decreases from 7 to 0 . The total production of white-tin bread is complemented with fermented breadcrumb bread in some parts of the frontier.

The curve presented in Fig. 4 shows a clear trade-off between economic and environmental objectives. This shape of the curve (determined by the non-dominated solutions found) can be 


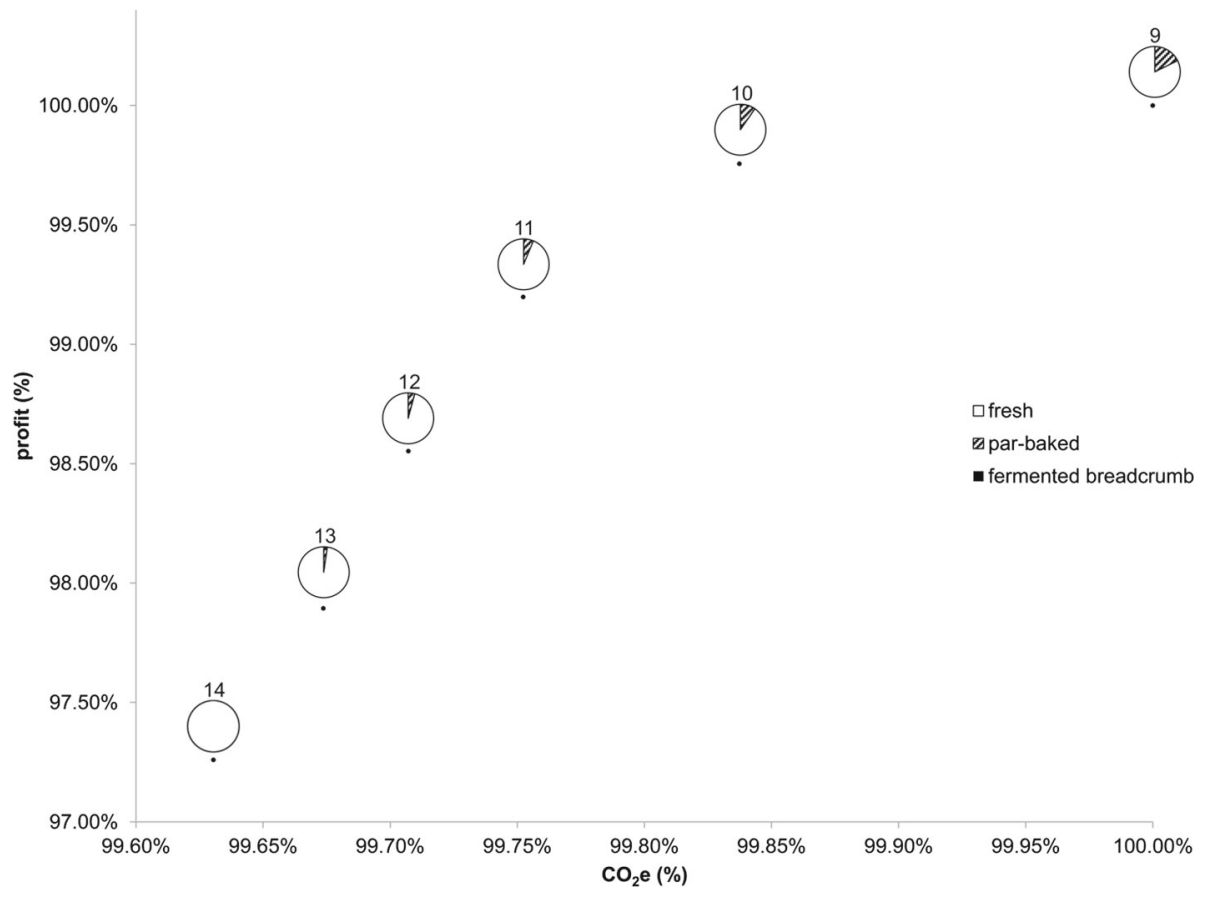

Fig. 5 Trade-off between profit and $\mathrm{CO}_{2} \mathrm{e}$; pie charts above solutions indicate amount of bread produced with each option as a fraction of total (weekly) production; numbers above pie charts indicate total number of setups for both bread types in the considered production plan

used to calculate the price of an improvement in environmental performance. For instance, for a production plan focusing only on profit maximization we can observe that for $0.17 \%$ (210€) of current profit we can improve the environmental performance by $2.45 \%$ (20,690 MJ).

\subsubsection{Eco-efficient solutions for other environmental objectives}

The impact of the selected environmental indicator on the eco-efficient frontier is investigated by expressing the environmental performance by other commonly used indicators in SC literature. In Figs. 5 and 6 two sets of eco-efficient solutions are presented, corresponding to two scenarios: where the environmental objective is represented with total amount of total amount of $\mathrm{CO}_{2} \mathrm{e}$, and waste generated, respectively.

Using $\mathrm{CO}_{2} \mathrm{e}$ as an environmental objective yields a trade-off curve with only 6 solutions (Fig. 5), and the best environmental solution when considering exergy losses (only parbaked bread) is different to the solution when using $\mathrm{CO}_{2} \mathrm{e}$ as an objective (only fresh bread). Analysis of this trade-off curve indicates that the production plan becomes more profitable by gradually changing the production for brown buns (white tin bread is freshly baked in each production option on the eco-efficient frontier) from fresh, to par-baked bread. This shows that apart from the best economic solution, all solutions on the eco-efficient frontier are different compared to considered scenarios where exergy loss is used as an environmental indicator.

We observe that using total amount of food waste generated as an objective for environmental performance (Fig. 6) yields nearly the same trade-off curve compared to scenario 


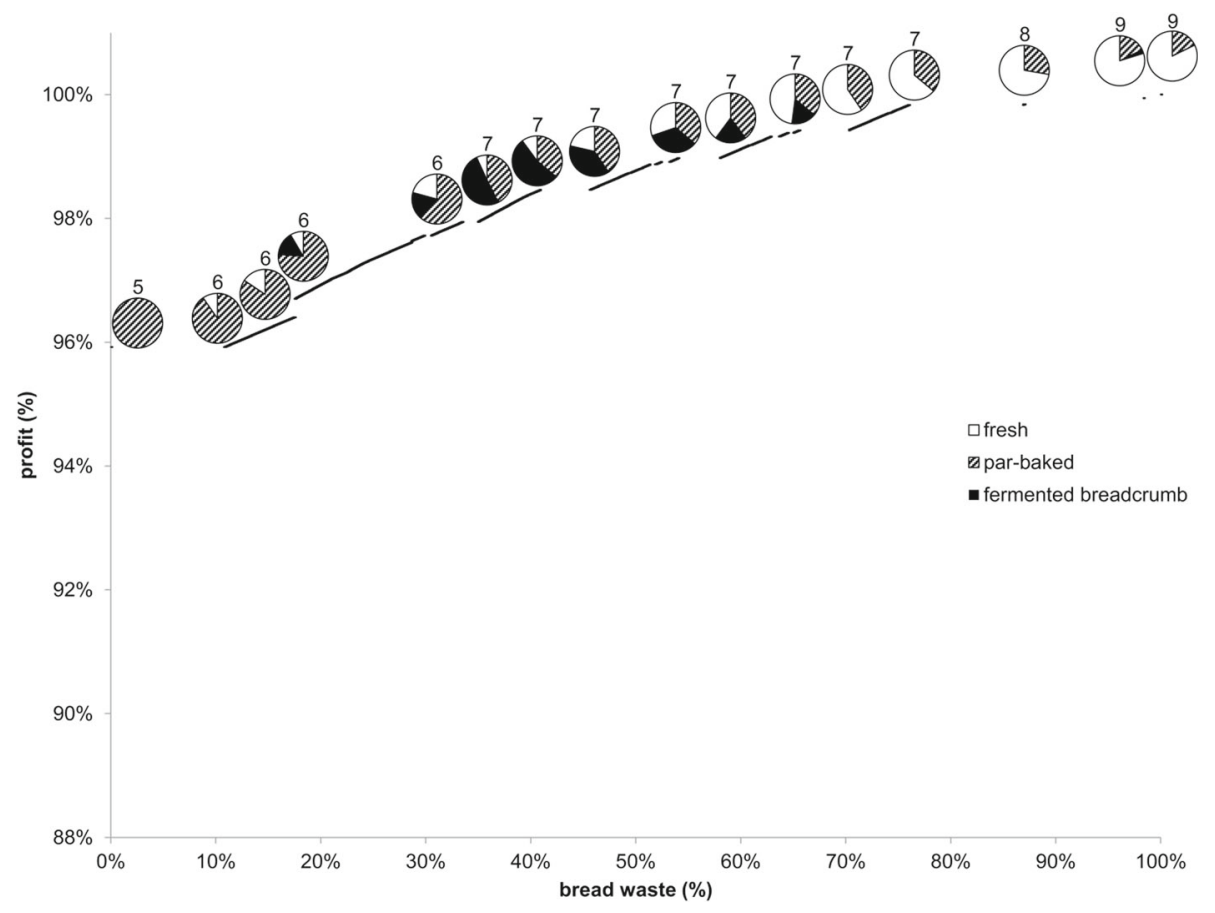

Fig. 6 Trade-off between profit and bread waste; pie charts above solutions indicate amount of bread produced with each option as a fraction of total (weekly) production; numbers above pie charts indicate total number of setups for both bread types in the considered production plan

when total exergy losses are used. The main difference is the absence of most solutions in which only par-baked bread is produced, i.e. nine solutions observed in the bottom left corner of Fig. 4. These solutions are not efficient when waste is the environmental objective, because they all correspond to solutions where no waste is produced (production with par-baked bread only). Overall, within the 10,000 iterations performed, $88 \%$ of efficient solutions when waste is considered as an environmental objective (Fig. 6), are also found on the eco-efficient frontier when exergy loss is considered as an environmental objective (Fig. 4). In the remaining $12 \%$ of efficient solutions, the average difference in total exergy losses is $0.11 \%$ as compared to solutions when exergy loss is considered. This shows that the eco-efficient frontier is nearly the same when waste and exergy loss is used. The reason for having nearly the same eco-efficient frontier is that total exergy losses are most heavily influenced by chemical exergy associated with bread waste.

\section{Sensitivity analysis}

Sensitivity analysis illustrates that the proposed model can be used to investigate the impact of parameter changes on the optimal solution. Results presented in previous section are based on the data obtained via collaboration with experts from industry. To make a reliable analysis, experts were involved before, during, and after the model development phase. While experts could estimate some model parameters relatively easy (e.g. bread prices, energy costs, labour costs, amount of bread waste for fresh bread production based on historical data), some other 


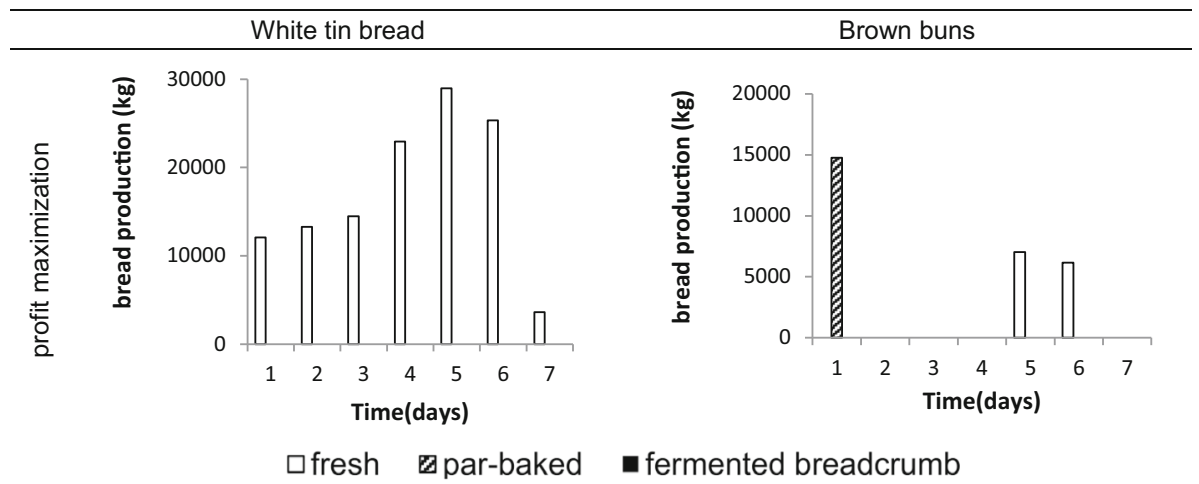

Fig. 7 Optimal economic production plan with $3 \%$ par-baked bread losses at the supermarket

parameters are rather difficult to measure, e.g. par-baked bread losses at the supermarket and setup costs. For the current data structure, par-baked bread production seems beneficial as it is the only option used to produce brown buns in all production plans in the eco-efficient frontier. Moreover, par-baked bread production is selected in most production plans for white tin bread, given the assumption of no losses at the supermarket. Additionally, (high) setup costs make par-baking beneficial because in this production option inventory is allowed. Therefore, based on discussion with experts, the primary focus of sensitivity analysis was examining the impact of a change in the following parameters: assumed amount of par-baked bread losses, and setup costs.

Additionally, it was examined whether the solutions obtained by maximizing profit and minimizing exergy losses are sensitive to changes in other parameters in the objective functions. We varied each parameter separately by changing its value in an interval between $50 \%$ decrease, and $100 \%$ increase for all production options simultaneously. We found that the optimal economic solution is not sensitive to changes within the examined interval for selling price, and inventory holding costs. Production costs, however, are more sensitive to changes in parameters. Decrease by $10 \%$ in production costs entails more production of par-baked white tin constituting to $22 \%$ of total white tin bread production. Increase in production costs by $46 \%$ makes fresh bread somewhat beneficial for brown buns, and constitutes to $48 \%$ of total brown buns production. With respect to environmental objective expressed with exergy loss, we found that changes in chemical exergy, exergy losses related to production, and exergy losses associated with holding, do not affect the optimal production plan.

\subsection{Par-baked bread losses}

To evaluate the consequences of having some losses in the par-baking option, we calculated optimal production plans assuming losses of par-baked bread between 1 and $10 \%$. Sensitivity on this parameter with respect to economic objective does not affect the production plan for white tin bread (freshly baked only). For brown buns, production of fresh bread appears in the optimal production plan when losses of par-baked bread are 3\% (Fig. 7) or higher. Par-baking, however, is still favourable and constitutes to more than $50 \%$ of the production for brown buns in each examined scenario (e.g. for $3 \%$ losses, par-baking is $52.8 \%$ of brown bun production).

When minimizing exergy losses (Fig. 8), fermented breadcrumb bread becomes the best option for white tin bread when losses of par-baked bread are $3 \%$ or more, because it offers the 


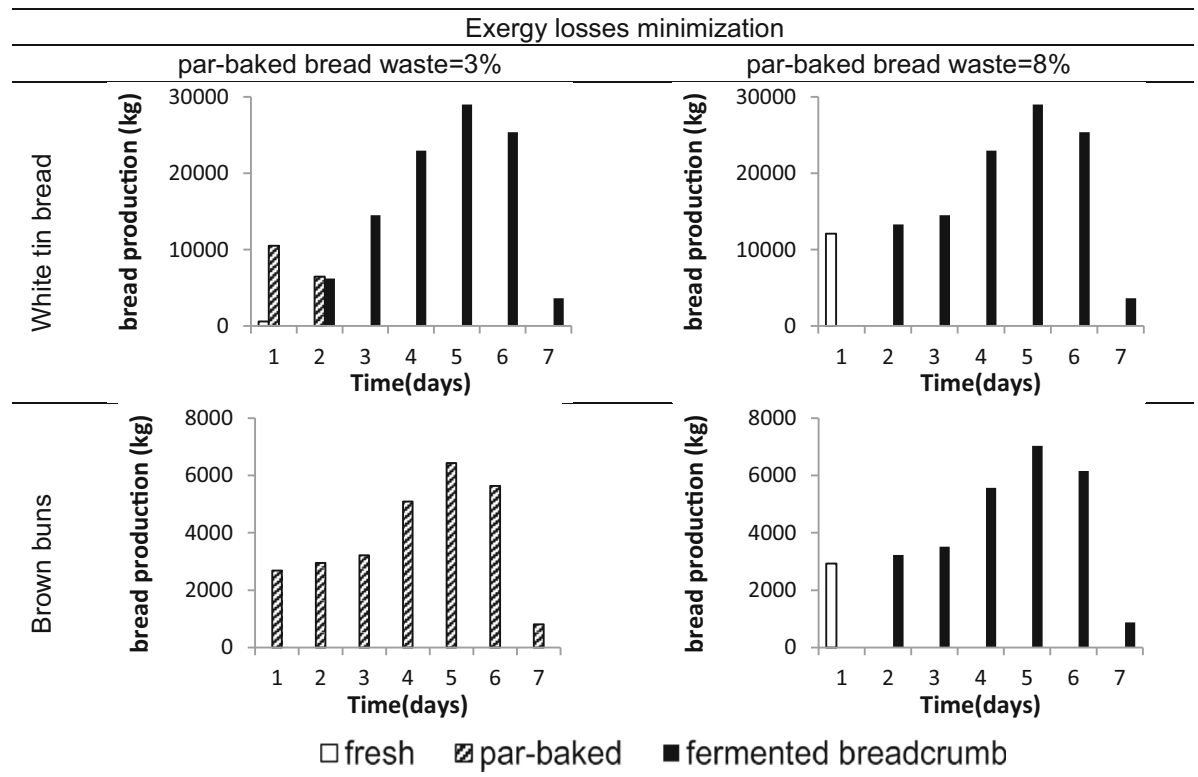

Fig. 8 Optimal environmental production plans with 3 and $8 \%$ par-baked bread losses at the supermarket

opportunity to valorise environmentally costly bread waste, which otherwise would result in exergy lost. Par-baking is preferred for brown buns until par-baked bread losses are lower than $8 \%$. Then, fermented breadcrumb bread becomes beneficial. In scenarios where fermented breadcrumb bread is produced it is observed that in the first time period(s) other production options are used, such that sufficient amount of waste is available, which is required as a raw material for fermented breadcrumb bread production.

\subsection{Setup costs}

Sensitivity analysis of setup costs affects only the profit maximization model run. Results are presented in Fig. 9. When setup costs are neglectable, production of fresh baked breads is most attractive (lowest variable costs, despite producing $11 \%$ waste). When setup costs are $2000 €$, par-baked production takes place for white tin bread to cover the lowest three demands thereby reducing the number of setups. On the second day full baking capacity is devoted to produce par-baked brown buns.

\section{Discussion and managerial insights}

In spite of the impact of parameter settings, some general conclusions and managerial insights can be drawn. From an economic point of view fresh bread is beneficial for the majority of bread products (white tin bread in our study), especially under low setup costs. The parbaking production option is interesting when set-up costs are high. An important managerial insight is that par-baking can bring economic benefits for some bread types (brown buns), if the management is able to react to the observed demand rapidly and minimize the losses. Therefore, par-baked bread production should be implemented as it can give economic and environmental benefits. The analysis also shows that the economic solution is hardly sensitive 


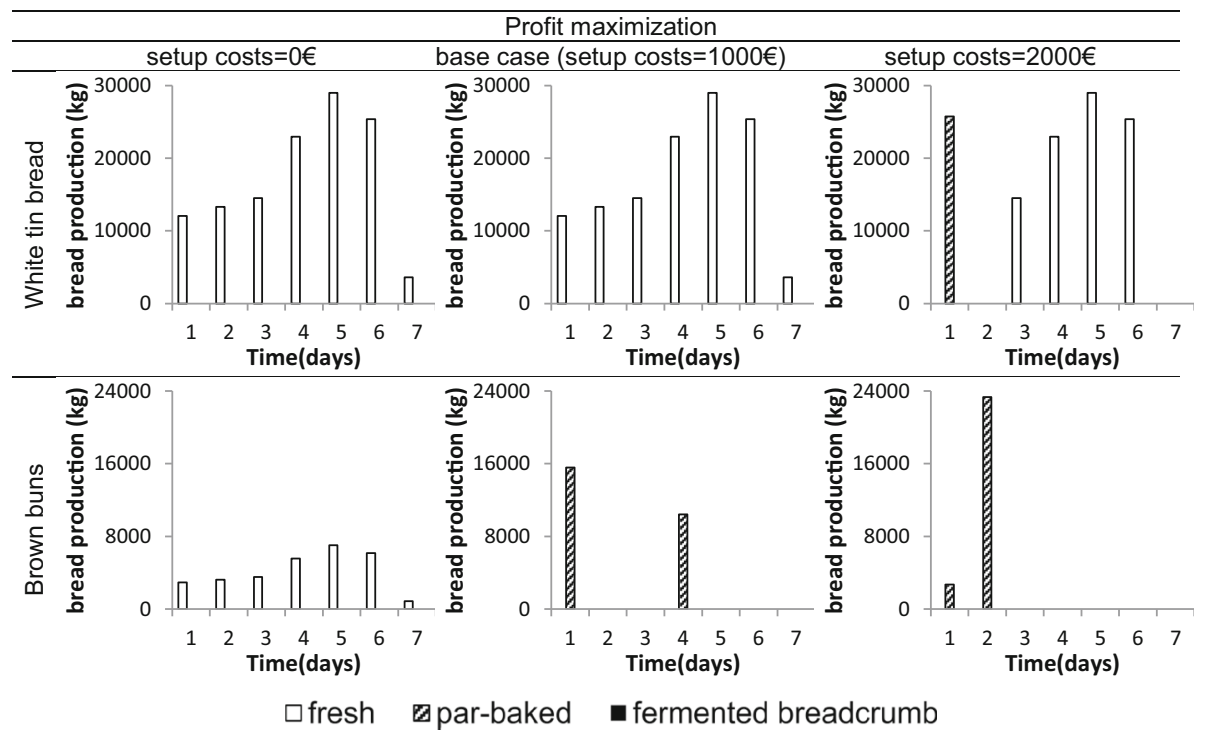

Fig. 9 Optimal economic production plans with 0, 1000, and $2000 €$ daily setup costs per bread type, per production option

to changes in the selling prices and inventory holding costs. However, changes in production costs have a clear impact on the quantities of par-baked and fresh bread, i.e. a decrease in production costs entails more production of par-baked bread, and an increase in these costs entails more production of freshly baked bread.

From the environmental perspective par-baking is beneficial for all bread types in the base case scenario. It turns out that exergy losses (chemical exergy, exergy losses related to production, and exergy losses associated with holding) hardly affect the optimal production plan. Fermented breadcrumb bread production can give better results if losses of par-baked bread are higher than a threshold value of $3 \%$. From a technological point of view, it is interesting to investigate if wasted bread, or processed wasted bread can be stored (and if so, for how long) and used as a raw material for fermented breadcrumb bread production after more than one day (as assumed here).

Sensitivity analysis shows that the preferred production option depends on parameter settings. Each production option is dominant in some scenario, depending on the overriding objective, and depending on used parameter values. Future research can help to determine more accurately the demand patterns, amount of waste at the supermarkets and setup costs.

We assumed that the selling price of bread is independent of the production option. In practice, the price of bread produced might be different between production options, which will have a direct effect on the results of our analysis.

\section{Conclusions and future research}

The main contribution of this study is the development of a model to assess alternative production options for waste management, by optimizing production planning decisions in food supply chains with respect to economic and environmental criteria. We fill the gap in 
literature by assessing the eco-efficiency of production options using a lot sizing model for a real-life case study, namely industrial bread supply chain in the Netherlands. Three options to produce a bread product are available, and each production alternative is associated with a different option to deal with waste, i.e. par-baked bread (prevention), fermented breadcrumb bread (recycling), and freshly baked bread (disposal). We found that prevention of waste appears to be the most beneficial solution for all bread types from an environmental point of view, what is in line with the guideline provided in the food waste hierarchy (Papargyropoulou et al. 2014). Prevention of waste is also beneficial for a fraction of all bread types from an economic point of view. The possibility to store par-baked bread and sell when is needed gives additional flexibility and reduces substantially the set-up costs. Shift to a par-baked bread production implies that shelf life of a product can be substantially extended, and this offers change in the design of a bread supply chain. These findings encouraged our industrial partners to carry out a follow up research to investigate the potential alternative logistical structures, including location and sizes of distribution centres, which are enabled due to par-baked bread production. Future research on this industrial bread supply chain should also investigate inventory management related issues, such as alternative reviewing policies, and safety stock levels of frozen breads. It is also important in future research to quantify production setup costs, to determine the accuracy of the demand patterns, and to investigate if (processed) bread waste can be stored before being used for production of fermented breadcrumb bread. The applicability of the model has been demonstrated by performing sensitivity analysis on input parameters. Sensitivity analysis revealed that optimal solutions depend on parameters not precisely known in advance, and we conclude that future research is needed to take into account uncertainty in parameters.

The environmental impact of the bread supply chain is expressed by the concept of exergy. We show in the case study that the optimal solutions obtained are different when exergy losses are used as an environmental indicator compared to a scenario in which the most commonly applied indicator, i.e. $\mathrm{CO}_{2}$ equivalents, is used. $\mathrm{CO}_{2}$ equivalents focuses only on specific issues, and does not always provide an integrated assessment of environmental impact. Using $\mathrm{CO}_{2}$ equivalents, therefore, may point to solutions that are not overall environmentally friendly. When environmental impact is expressed with the total amount of bread waste generated, solutions obtained are nearly the same as when exergy losses are used. This confirms that exergy is able to capture both energy and waste impact, and provides some evidence that exergy analysis offers an objective assessment of environmental impact. Future case studies are needed to confirm this.

In the study we illustrated the potential of studying food production planning problems in a multi-objective context, and demonstrate that the developed model can provide insights in assessment of alternative production options.

Financial disclosure The project is funded by TI Food and Nutrition, a public-private partnership on precompetitive research in food and nutrition. The public partners are responsible for the study design, data collection and analysis, decision to publish, and preparation of the manuscript. The private partners have contributed to the project through regular discussion.

\section{Compliance with ethical standards}

Conflict of interest The authors have declared that no competing interests exist.

Open Access This article is distributed under the terms of the Creative Commons Attribution 4.0 International License (http://creativecommons.org/licenses/by/4.0/), which permits unrestricted use, distribution, and reproduction in any medium, provided you give appropriate credit to the original author(s) and the source, provide a link to the Creative Commons license, and indicate if changes were made. 


\section{Appendix 1}

\begin{tabular}{|c|c|c|c|c|c|c|}
\hline \multirow[t]{2}{*}{ Activity associated with exergy losses } & \multicolumn{3}{|c|}{ White tin } & \multicolumn{3}{|c|}{ Brown bun } \\
\hline & Fresh & Par-baked & $\begin{array}{l}\text { Ferm. } \\
\text { bread. }\end{array}$ & Fresh & Par-baked & $\begin{array}{l}\text { Ferm. } \\
\text { bread. }\end{array}$ \\
\hline Transport raw materials $(\mathrm{MJ} / \mathrm{kg})$ & 0.09 & 0.09 & 0.09 & 0.09 & 0.09 & 0.10 \\
\hline Mixing, fermenting, dividing, proving (MJ/kg) & 1.22 & 1.21 & 1.28 & 1.22 & 1.19 & 1.36 \\
\hline Baking $(\mathrm{MJ} / \mathrm{kg})$ & 2.28 & 1.99 & 2.57 & 2.25 & 1.66 & 2.67 \\
\hline Cooling (MJ/kg) & 0.31 & - & 0.24 & 0.60 & - & 0.60 \\
\hline Freezing (MJ/kg) & - & 0.90 & - & - & 1.00 & - \\
\hline Packing (MJ/kg) & 0.01 & 0.00 & 0.01 & 0.02 & 0.00 & 0.02 \\
\hline Transport bread (MJ/kg) & 0.56 & 0.55 & 0.56 & 0.56 & 0.55 & 0.56 \\
\hline Final baking $(\mathrm{MJ} / \mathrm{kg})$ & - & 0.91 & - & - & 0.91 & - \\
\hline Processing waste $(\mathrm{MJ} / \mathrm{kg})$ & - & - & 0.05 & - & - & 0.22 \\
\hline
\end{tabular}

\section{Appendix 2}

\begin{tabular}{|c|c|c|c|c|c|c|}
\hline \multirow[t]{2}{*}{ Component of production costs } & \multicolumn{3}{|c|}{ White tin } & \multicolumn{3}{|c|}{ Brown bun } \\
\hline & Fresh & Par-baked & $\begin{array}{l}\text { Ferm. } \\
\text { bread. }\end{array}$ & Fresh & Par-baked & $\begin{array}{l}\text { Ferm. } \\
\text { bread. }\end{array}$ \\
\hline \multicolumn{7}{|l|}{$\begin{array}{l}\text { Electricity consumption }(\mathrm{MJ} / \mathrm{kg}) \\
\quad(\text { price }=0.03 € / \mathrm{MJ})\end{array}$} \\
\hline Mixing, dividing, proving & 1.06 & 1.05 & 1.22 & 1.03 & 1.00 & 1.28 \\
\hline Cooling/freezing & 0.22 & 0.89 & 0.21 & 0.21 & 0.98 & 0.21 \\
\hline Packing & 0.01 & 0.00 & 0.01 & 0.02 & 0.00 & 0.02 \\
\hline Processing waste into sourdough & - & - & 0.04 & - & - & 0.04 \\
\hline \multicolumn{7}{|l|}{$\begin{array}{l}\text { Natural gas consumption }(\mathrm{MJ} / \mathrm{kg}) \\
\quad(\text { price }=0.01 € / \mathrm{MJ})\end{array}$} \\
\hline Baking & 2.15 & 1.86 & 2.48 & 2.11 & 1.51 & 2.59 \\
\hline Final baking & - & 0.89 & - & - & 0.89 & - \\
\hline \multicolumn{7}{|l|}{$\begin{array}{l}\text { Fuel consumption }(\mathrm{L} / \mathrm{kg}) \\
\quad(\text { price }=1.47 € / \mathrm{L})\end{array}$} \\
\hline Raw materials transport & 0.0023 & 0.0023 & 0.0025 & 0.0024 & 0.0023 & 0.0026 \\
\hline Bread transport & 0.0147 & 0.0144 & 0.0147 & 0.0147 & 0.0144 & 0.0147 \\
\hline \multicolumn{7}{|l|}{ Recipe for $1 \mathrm{~kg}$ of bread $(\mathrm{kg})$} \\
\hline Flour $(0.34 € / \mathrm{kg})$ & 0.72 & 0.72 & 0.67 & 0.32 & 0.31 & 0.31 \\
\hline Whole meal $(0.34 €$ €/kg) & - & - & - & 0.32 & 0.31 & 0.31 \\
\hline Water $(0.00 € / \mathrm{kg})$ & 0.42 & 0.42 & 0.44 & 0.38 & 0.37 & 0.40 \\
\hline Yeast $(3.50 € / \mathrm{kg})$ & 0.01 & 0.01 & 0.01 & 0.04 & 0.04 & 0.03 \\
\hline Salt $(0.14 € / \mathrm{kg})$ & 0.01 & 0.01 & 0.01 & 0.04 & 0.04 & 0.03 \\
\hline Bread improver $(2.32 € / \mathrm{kg})$ & 0.01 & 0.01 & 0.01 & 0.01 & 0.01 & 0.01 \\
\hline Waste $(0.00 € / \mathrm{kg})$ & - & - & 0.06 & - & - & 0.07 \\
\hline Enzymes $(4.00 € / \mathrm{kg})$ & - & - & 0.002 & - & - & 0.002 \\
\hline Labour costs $(€ / \mathrm{kg})$ & 0.25 & 0.28 & 0.28 & 0.25 & 0.28 & 0.28 \\
\hline Packaging costs $(€ / \mathrm{kg})$ & 0.02 & 0.14 & 0.02 & 0.05 & 0.20 & 0.05 \\
\hline
\end{tabular}




\section{References}

Akkerman, R., Wang, Y. \& Grunow, M. (2009). Milp approaches to sustainable production and distribution of meal elements. In International conference on computers and industrial engineering 2009, CIE 2009 (pp. 973-978).

Apaiah, R. K., Hendrix, E. M. T., Meerdink, G., \& Linnemann, A. R. (2005). Qualitative methodology for efficient food chain design. Trends in Food Science and Technology, 16, 204-214.

Apaiah, R. K., Linnemann, A. R., \& Van Der Kooi, H. J. (2006). Exergy analysis: A tool to study the sustainability of food supply chains. Food Research International, 39, 1-11.

Aramyan, L., Hoste, R., Van Den Broek, W., Groot, J., Soethoudt, H., Nguyen, T. L., et al. (2011). Towards sustainable food production: A scenario study of the European pork sector. Journal on Chain and Network Science, 11, 177-189.

Blonk, H. (2006). Duurzaam broodbakken: Werkdocument analysefase bakker Wiltink. Gouda: Blonk Milieu Advies.

Braungart, M., Mcdonough, W., \& Bollinger, A. (2007). Cradle-to-cradle design: Creating healthy emissionsA strategy for eco-effective product and system design. Journal of Cleaner Production, 15, 1337-1348.

Chaabane, A., Ramudhin, A., \& Paquet, M. (2011). Designing supply chains with sustainability considerations. Production Planning \& Control, 22, 727-741.

Chaabane, A., Ramudhin, A., \& Paquet, M. (2012). Design of sustainable supply chains under the emission trading scheme. International Journal of Production Economics, 135, 37-49.

Claassen, G. D. H. \& Hendrix, E. M. T. (2014). On modelling approaches for planning and scheduling in food processing industry. Lecture notes in computer science (including subseries lecture notes in artificial intelligence and lecture notes in bioinformatics).

Chanta, S., Mayorga, M. E., \& McLay, L. A. (2014). Improving emergency service in rural areas: a bi-objective covering location model for EMS systems. Annals of Operations Research, 221, 133-159.

Clark, A., Almada-Lobo, B., \& Almeder, C. (2011). Lot sizing and scheduling: Industrial extensions and research opportunities. International Journal of Production Research, 49, 2457-2461.

Coatanéa, E., Kuuva, M., Makkonnen, P. E., Saarelainen, T. \& Castillón-Solano, M. O. (2006). Analysis of the concept of sustainability: Definition of conditions for using exergy as a uniform environmental metric. In Proceedings of the 13th CIRP international conference on life cycle engineering, 2006 ( $\mathrm{pp}$. 81-86).

Cortez, L. A. B., Larson, D. L., \& Da Silva, A. (1997). Energy and exergy evaluation of ice production by absorption refrigeration. Transactions of the American Society of Agricultural Engineers, 40, 395-403.

Das, I., \& Dennis, J. E. (1997). A closer look at drawbacks of minimizing weighted sums of objectives for Pareto set generation in multicriteria optimization problems. Structural Optimization, 14, 63-69.

Draganovic, V., Jørgensen, S. E., Boom, R., Jonkers, J., Riesen, G., \& Van Der Goot, A. J. (2013). Sustainability assessment of salmonid feed using energy, classical exergy and eco-exergy analysis. Ecological Indicators, 34, 277-289.

Ehrgott, M. (2005). Multicriteria optimization. Berlin: Springer.

FAO. (2013). Food wastage footprint; impacts on natural resources. Rome: FAO.

Govindan, K., Jafarian, A., Khodaverdi, R., \& Devika, K. (2014). Two-echelon multiple-vehicle locationrouting problem with time windows for optimization of sustainable supply chain network of perishable food. International Journal of Production Economics, 152, 9-28.

Harris, I., Naim, M., Palmer, A., Potter, A., \& Mumford, C. (2011). Assessing the impact of cost optimization based on infrastructure modelling on $\mathrm{CO}_{2}$ emissions. International Journal of Production Economics, $131,313-321$.

Jans, R., \& Degraeve, Z. (2008). Modeling industrial lot sizing problems: A review. International Journal of Production Research, 46, 1619-1643.

Kotas, T. J. (1995). The exergy method of thermal plant analysis. Malabar, FL: Krieger Publishing.

Mavrotas, G. (2009). Effective implementation of the $\varepsilon$-constraint method in multi-objective. Mathematical Programming Problems, 213, 455-465.

Miettinen, K. (2008). Introduction to multiobjective optimization: Noninteractive approaches. In J. Branke, K. Deb, K. Miettinen, \& R. Słowinski (Eds.), Multiobjective optimization. Berlin: Springer.

Morris, D. R. (1991). Exergy analysis and cumulative exergy consumption of complex chemical processes: The industrial chlor-alkali processes. Chemical Engineering Science, 46, 459-465.

Oglethorpe, D. (2010). Optimising economic, environmental, and social objectives: A goal-programming approach in the food sector. Environment and Planning A, 42, 1239-1254.

Paksoy, T., Özceylan, E. \& Weber, G. W. (2010). A multi objective model for optimization of a green supply chain network. In AIP conference proceedings (pp. 311-320). 
Papargyropoulou, E., Lozano, R., Steinberger, K., Wright, N., \& Ujang, Z. B. (2014). The food waste hierarchy as a framework for the management of food surplus and food waste. Journal of Cleaner Production, 76, $106-115$.

Pochet, Y., \& Wolsey, L. A. (2006). Production planning by mixed integer programming. New York: Springer.

Quadt, D., \& Kuhn, H. (2008). Capacitated lot-sizing with extensions: A review. 4OR, 6, 61-83.

Quariguasi Frota Neto, J., Walther, G., Bloemhof, J., Van Nunen, J. A. E. E., \& Spengler, T. (2009). A methodology for assessing eco-efficiency in logistics networks. European Journal of Operational Research, 193, $670-682$.

Shukla, M., \& Jharkharia, S. (2013). Agri-fresh produce supply chain management: A state-of-the-art literature review. International Journal of Operations and Production Management, 33, 114-158.

Soysal, M., Bloemhof-Ruwaard, J. M., \& Van Der Vorst, J. G. A. J. (2014). Modelling food logistics networks with emission considerations: The case of an international beef supply chain. International Journal of Production Economics, 152, 57-70.

Validi, S., Bhattacharya, A., \& Byrne, P. J. (2014). A case analysis of a sustainable food supply chain distribution system-A multi-objective approach. International Journal of Production Economics, 152, 71-87.

Van Der Vorst, J. G. A. J., Tromp, S. O., \& Van Der Zee, D. J. (2009). Simulation modelling for food supply chain redesign; integrated decision making on product quality, sustainability and logistics. International Journal of Production Research, 47, 6611-6631.

Wall, G. (2010). On exergy and sustainable development in environmental engineering. The Open Environmental Engineering Journal, 3, 21-32.

You, F., Tao, L., Graziano, D. J., \& Snyder, S. W. (2012). Optimal design of sustainable cellulosic biofuel supply chains: Multiobjective optimization coupled with life cycle assessment and input-output analysis. AIChE Journal, 58, 1157-1180.

Zanoni, S., \& Zavanella, L. (2012). Chilled or frozen? Decision strategies for sustainable food supply chains. International Journal of Production Economics, 140, 731-736.

Zisopoulos, F. K., Moejes, S. N., Rossier-Miranda, F. J., Van Der Goot, A. J., \& Boom, R. M. (2015). Exergetic comparison of food waste valorization in industrial bread production. Energy, 82, 640-649. 